\title{
MOTIVATIONS FOR STUDYING DENTISTRY AND DENTAL COLLEGE PREFERENCE AMONG RAS AL KHAIMAH COLLEE OF DENTALSCIENCES (RAKCODS) STUDENTS
}

\author{
Jumma 0. S. Alkhabulii ${ }^{1 a^{*}}$, Amar Hassan Khamis ${ }^{2 b}$ \\ ${ }^{1}$ Basic Dental Sciences Department, RAK College of Dental Sciences, RAKMHSU - Ras Alkhaimah Medical and Health Sciences University, Ras \\ Alkhaimah, UAE \\ ${ }^{2}$ Biostatistics and Genetic Epidemiology Department, Hamdan Ben Mohammed College of Dental Medicine, Dubai, UAE \\ aBDS, MDentSci, MFDS RCPS (Glas), FICD, PhD (Leeds, UK), Associate Professor, head \\ bPhD, DEA, MSc, BSc, Associate Professor
}

Cite this article:

Alkhabuli JOS, Khamis AH. Motivations for studying dentistry and dental college preference among Ras Al Khaimah College of Dental Sciences (RAKCODS) students. Stoma Edu J.2016;3(3-4):141-149.

Objectives: The objectives of this study were to find out the reasons for choosing dentistry as a future career and the factors for preferring Ras Al Khaimah College of Dental Sciences students over other dental colleagues in UAE.

Methods: A cross sectional questionnaire comprised of 19 items related to the dental career and 6 items related to RAKCODS preference factors were sent electronically to the 1st year (2014-2015) and 2nd year (2013-2014) RAKCODS students. The responses on the students' motivation were collected using three-point ordinal scales. The data were analyzed using SPSS, v16 program. T-test and Chi-Square test were used to measure the level of differences.

Results: The overall response rate was $67.0 \%(n=110)$. The mean age was 18.9 years. Females represented $63.6 \%$ and males $36.4 \%$ of the respondents. The important motives were "interest to treat people and improve their oral health" by $73.6 \%$, "dental practice is a combination of hand skills and knowledge" by $66.4 \%$, "dental profession provides option to be self-employed" by $61.8 \%$ and "dentistry has high-level income of practice" by $60 \%$. Females showed significant difference to males in treatment of people and oral health care motive $(p=0.022)$. Dentistry has high income and pays better were important factors for males more than for females $(p=0.033$ and $p<0.001)$ respectively. The curriculum comparable to international standard and the fascinating facilities were the most significant preference factors of RAKCODS.

Conclusion: The motives towards a dental career were mainly to improve peoples' oral health, have high income and to be a self-employed professional. Curriculum and facilities were the most attracting factor of RAKCODS.

Keywords: professional practice, dental, career choice, students, United Arab Emirates.

\section{Background}

Ras Al-Khaimah (RAK) is one of the seven emirates that comprise the United Arab Emirates (UAE) of 300.000 inhabitants ${ }^{1}$. The RAK College of Dental Sciences (RAKCODS) was established in 2007 as one of the four constituent professional Colleges of the RAK Medical and Health Sciences University (RAKMHSU). It was the third dental college to be established in UAE and it is fully accredited by the higher ministry of education and scientific research.

The college started with 13 students on board in a humble building and with not enough facilities in 2007. Since its inception, there has been gradual increase in the number of admitted students. In the academic year 2012-2013, the college moved into a state of the art building, and modern facilities that can accommodate up to 80 students per academic year.

Since then, there has been a sharp increase in the number of students seeking admission to RAKCODS. A total of 38 qualified dental surgeons have graduated from RAKCODS so far.

The UAE society is a diverse community living in a very peaceful environment. The varied ethnicity has echoed in the different backgrounds of the students making up the academic community, with different levels of educations, personal characters

\section{*Corresponding author:}

Associate Professor Juma 0. S. Alkhabuli, head of Basic Dental Sciences Department, BDS, MDentSci, MFDS RCPS (Glas), FICD, PhD (Leeds, UK) 
and motivations towards prospective professions. Dentistry is a well-respected and reputable profession in societies all over the world. Several factors may govern or modulate the decision of pursuing this field. Traditionally, several factors have been recognized that may influence one's decision to choose dentistry as a future career including oral health promotion, assisting and working in societies, availability and ease of employment, financial security, prestige, provision of enough time off for family life, desire to work in health care and making a good income $e^{2-6}$.

Interestingly, variation in social background, race, gender and country have been found to influence career selection as well7-10. In the United States of America for example, it has been reported that African-American students were more inclined to serve the community, while the Caucasian-American students' motivation to graduate as a dentist was related to fulfilling family commitments ${ }^{11}$. In a study by Khami and his colleagues ${ }^{12}$, social status and security were ranked amongst the highest by the students. Many students consider the dental profession as prestigious. In a study involving more than 400 students prestige topped the other factors scoring $44.4 \%$ and helping other people came second: $43.6 \%{ }^{13}$.

A substantial percentage of people in many communities cannot afford dental treatment. Government clinics are usually congested and limited to emergency and basic dental services. Thus, many authors explored altruism and empathy towards the population's oral health status as motives among the students, however, many reports failed to show a great impact of these factors on the choice of a dental career, particularly among male students.

Several publications have demonstrated that gender differences are some of the driving forces of the career. Females appeared to be more motivated to promote oral health and care than males $^{9,14}$. In a piece of research involving four dental colleges in South Africa, Lallo and his group ${ }^{15}$ found racial differences as one of the motivations amongst the surveyed students, mainly in terms of finance, post-graduation practice, community services and financial debts.

Freire and colleagues ${ }^{6}$, in a cross-sectional study used a self-administered questionnaire to investigate ambitions and motives to choose a dental career of all first-year students enrolled in the 1993-95 and 2006-08 periods in one of the Brazilian dental.

The report found significant differences in the freshmen's motivations and various professional perspectives overtime. The study revealed diverse personal views over the influencing factors in pursuing a dental career among students.

\section{Aim of the study}

The objectives of this study were to investigate the driving motives and influential factors of RAKCODS students towards choosing dentistry as their future career, and whether there were any specific reasons for preferring RAKCODS over other dental colleges in UAE.

\section{Methods}

The research proposal was approved by the research and ethics committee of RAKMHSU, reference number (RAKMHSU-REC-1-2015-F-D). A selfadministered questionnaire with three sections ( $A$, $B$ and $C$ ) was constructed using previously reports published in the literature. The first section (A) covered demographic information including age, gender, nationality and high school curriculum. The second part (B) included 19 items inquiring about the potential influential factors in choosing a dental career. The third section (C) consisted of six questions probing the reasons for preferring RAKCODS as a college to pursue a dental career. Responses on students' motivation were collected using threepoint ordinal scales "important, less important, not important".

A total of 164 registered students were included in the survey. They were students who had just finished their first academic year 2013-2014 and newly admitted students for the academic year 2014-2015. The questionnaire was pretested on 40 students. A correction of ambiguity was performed on all items and prepared for the online survey. The students were approached via their universityemail ID and a message was sent to the respective students explaining the online questionnaire, its voluntary nature, the need for honesty in answering the questions and the need for acceptance to participate in the research. A clear statement was written in the message denoting that a response to the questionnaire would be considered as their consent. The online-link to the questionnaire was emailed to the respective academic year students and activated for three weeks. Three reminder emails were sent to the students with a one week interval requesting completion of the questionnaire. The survey allows only one answer to be selected for each variable and the system only accepts the fully answered questionnaires. By the end of the third week the questionnaire link was deactivated and the data were saved as an Excel file. 
Dear Dental students,

Welcome to the college of dental sciences, RAKMHSU. We are conducting a survey, right the beginning of the academic year on the reasons that made you to select dentistry as your future profession.

Your name is not required but your age, gender and the curriculum that you have chosen to obtain your high school certificate are important.

Please be honest while answering the following questions.

\section{Section A:}

- Gender: M F

- Age: $\quad$.......... years

- Nationality:

- High school Curriculum:

- British

- American

- Indian

- Pakistan

- Arabic

- Persian

- Australian

- Others

\section{Section B:}

Which of the following factors made you choose Dentistry as your future career?

\begin{tabular}{|c|l|c|c|}
\hline \multicolumn{1}{|c|}{$\begin{array}{l}\text { S. } \\
\text { No. }\end{array}$} & \multicolumn{1}{|c|}{ Factor } & \multicolumn{1}{|c|}{} \\
& & & \\
\hline 1 & On recommendation of a friend/ relative & & \\
\hline 2 & Because one of my parents is a dentist & & \\
\hline 3 & It's easy for dentists to find work employment & & \\
\hline 4 & Dentistry pays better than other job options available to me & & \\
\hline 5 & Dental profession provides option to be self-employed & & \\
\hline 6 & Ihave keen interest to treat/help people to improve their oral health & & \\
\hline 7 & Dentistry has high-level income of practice & & \\
\hline 8 & Dentistry provides short cut to health care specialty & & \\
\hline 9 & Developed interest from my family dentist & & \\
\hline 10 & A career in dentistry offers job security & & \\
\hline 11 & Dentists have a flexible work schedule & & \\
\hline 12 & Dental career provides enough time to be with family & & \\
\hline 13 & Dental practice is a combination of hand skills and knowledge & & \\
\hline 14 & There is not much "on call" work for dentists & & \\
\hline 15 & Motivation by marketing/dental professionals during high school & & \\
\hline 16 & Dentistry is a prestigious profession & & \\
\hline 17 & Worked in other dental related fields and now I want to be a dentist & & \\
\hline 18 & Dentists do not need to deal with life threatening conditions & & \\
\hline 19 & Failure to be admitted to other programs, like Medicine & & \\
\hline
\end{tabular}

\section{Section C:}

Why did you choose RAKMHSU to pursue Dentistry?

\begin{tabular}{|l|l|l|l|l|}
\hline 20 & Because RAK is my home (convenience) & & & \\
\hline 21 & Tuition fees are less than other dental colleges & & & \\
\hline 22 & I could not get admission in other dental colleges in UAE & & & \\
\hline 23 & I was transferred from other dental colleges in UAE & & & \\
\hline 24 & RAKCODS curriculum is comparable to international standard & & & \\
\hline 25 & RAKCODS has fascinating building and very good facilities & & & \\
\hline
\end{tabular}

*RAKMHSU: Ras Alkhaimah Medical and Health Sciences University

**Please notice, answering this questionnaire is your consent to participate in the survey. 


\section{Results}

Before analyzing the results, the column in the data Excel file indicating the students' emails was deleted, to keep the data anonymous. As there is no loss of data or unanswered questions among all subjects, the data will be projected mainly in percentages.

Out of 164 students 110 completed the online questionnaire with a response rate of $67.0 \%$ and a mean age of 18.9 (range 16-25). $63.6 \%$ of the participants were females and $36.4 \%$ were males. With regard to the curricula they studied; 61 (55.5\%) of the students completed Arabic high school curriculum and 27 (24\%) completed British curriculum (Table 1). The respondents' ethnicity was uneven with the majority from Bahrain 20 (18.0\%) followed by Syrian and Iraqi 16 (14.4\%) and $15(13.5 \%)$ respectively (Fig. 1).

Fig. 2 shows the respondents' reasons for choosing dentistry as a career and level of importance. Of these, "Have interest to treat people \& improve their oral health" (73.6\%), "Dental practice is a combination of hand skills and knowledge"
(66.4\%), "Dental profession provides option to be self-employed" (61.8) and "Dentistry has high-level income of practice" (60.0\%) were the predominant influences. A high percentage of the respondents thought the dental profession provides a flexible work schedule and adequate time to spend with the family (52.7\%) and (56.4\%) respectively. Half of the respondents thought dentistry is a prestigious profession. In $30 \%$ of the respondents the dental career was chosen on a recommendation by friends or relatives. Many students (42.7\%) thought pursuing dentistry would make the process of hunting a job much easier. A high percentage $(47.3 \%)$ assumed that dentistry offers a short cut to the health care profession without need for further studies. A low percentage of respondents (18.2\%) were admitted to dentistry as a second option after failing to obtain other programs. The motivation programs offered by the college marketing professionals during school time were important for $21.8 \%$ of the respondents. Only $(4.5 \%)$ of the students were influenced by their dentist parents in choosing the dental career.

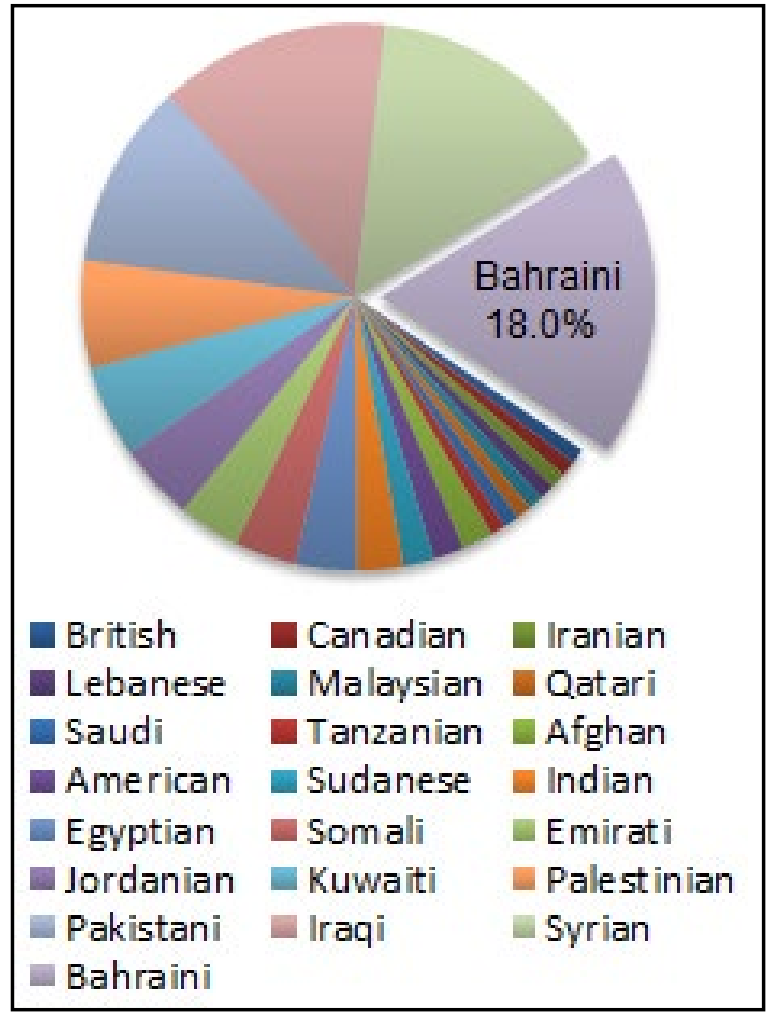

Figure 1. Nationalities of the respondents

Table 1. Showing the frequency and percentages of students and the studied curricula at high school level

\begin{tabular}{|c|c|}
\hline Curriculum & $\mathbf{n}(\%)$ \\
\hline American & $12(10.9 \%)$ \\
\hline Arabic & $61(55.5 \%)$ \\
\hline British & $27(24.5 \%)$ \\
\hline Canadian & $2(1.8 \%)$ \\
\hline British and American & $1(0.9 \%)$ \\
\hline Indian & $3(2.7 \%)$ \\
\hline International Baccalaureate & $1(0.9 \%)$ \\
\hline Kuwaiti & $1(0.9 \%)$ \\
\hline Persian & $2(1.8 \%)$ \\
\hline
\end{tabular}


Table 2 shows the ranking of factors that influenced the respondents to prefer RAKCODS over other dental colleges. Almost half of the students preferred the college because of the resemblance between the curriculum and the international standard followed by the fascinating building and availability of the facilities. Relatively low tuition fees were ranked as the third reason for choosing RAKCODS. About (21\%) of the respondents accepted RAKCODS, as they could not secure a seat in the other dental colleges (rank 4).

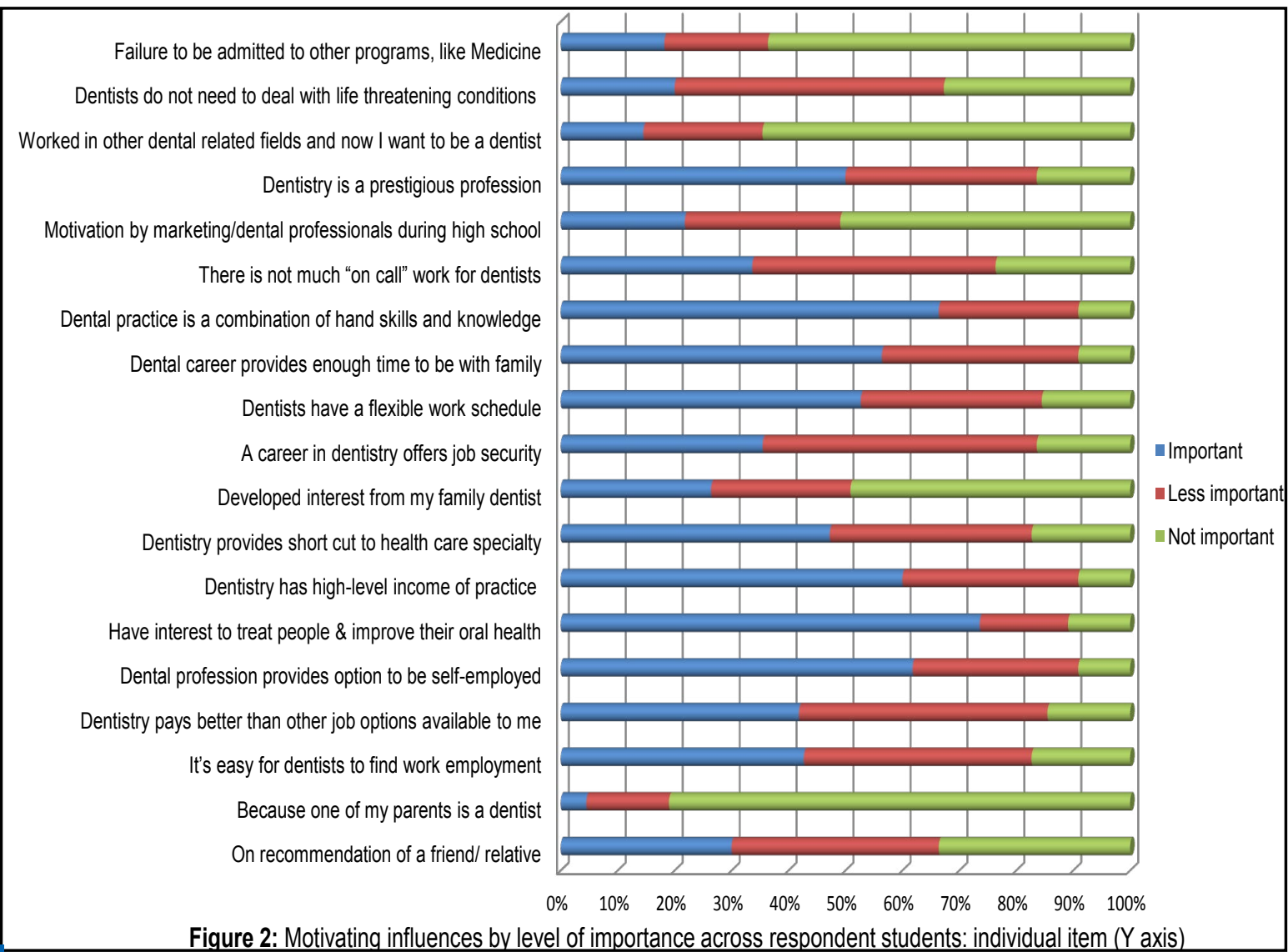

Figure 2. Motivating influences by level of importance across respondent students: individual item ( $Y$ axis) and proportion of students selecting each item ( $X$ axis) $(n=110)$

Table 2. Respondents' reasons for choosing RAKCODS as institute to study dentistry

\begin{tabular}{|l|c|c|}
\hline \multicolumn{1}{|c|}{ Factors } & $\%$ & Rank \\
\hline RAKCODS curriculum is comparable to international standard & 48.2 & First \\
\hline RAKCODS has fascinating building and very good facilities & 47.3 & Second \\
\hline Tuition fees are less than other dental colleges & 27.3 & Third \\
\hline I could not get admission in other dental colleges in UAE & 20.9 & Fourth \\
\hline Because RAK is my home (convenience) & 10.0 & Fifth \\
\hline I was transferred from other dental colleges in UAE & 3.6 & Sixth \\
\hline
\end{tabular}

\subsection{Statistical analysis}

The variables in (Fig. 2) were given score 2 for important, 1 for less important and 0 for not important in a range between (0-38).

The score of dental career motivation factors was normally distributed with a mean of (20.14) and SD (6.433). This provides us with an idea about how likely our students were to consider being logic and confident in choosing the career as an important factor. From high possible expected score of 38 points, the students on average score $20 \pm 1.2$ as confidence Interval of their score factors. With respect to confidence as an important factor, we expected the highest possible score, namely 38 points, yet the average score the students got was $20 \pm 1.2$. This would locate the level of this chosen variable as an important factor in choosing this profession somewhere between 50\%-56\%. Generally, this indicates that the factor they chose was not based on logical assumption. 
Gender as well was not a factor which was systematically chosen for the dental career. 70 female students had a score of (20.86) and SD (6.7), while the 40 males had a score of (21.6) and SD (6.0) and p-value (0.549).

The students were grouped into freshly registered students, namely the (16-20) year old group and late registered students, namely above (20) years of age and tested against the score of factors; the study revealed that the mean of score of the 99 fresh students was (21.3), SD (6.2), while for the elder (late) group (11 students) the score was (19.9), SD (8.5) and p-value 0.507.

The high school curriculum variable was recorded as Arabic-based curricula and others. Again, the study showed no difference between the score of factors to choose dentistry as a career. About
62 students selecting the Arabic curricula made an average of score (21.45), SD (6.5), while 48 students coming from other background curricula made an average of (20.6), SD (6.3) with p-value 0.448 .

However, the variables were also directly correlated with the gender using Chi-Square Test. The test yielded three significant correlations (Table 3). Treatment and improvement of peoples' oral health was considered as an important factor by female respondents more than males $(p=0.022)$. On the other hand, the male respondents indicated that dentistry has high income and pays better than other jobs, so these were considered as important factors by higher percentages than females $(p=0.033$ and $p<0.001)$ respectively.

Table 3. The dental career factors demonstrating significant gender differences

\begin{tabular}{|l|l|c|}
\hline \multicolumn{1}{|c|}{ Variable } & \multicolumn{1}{|c|}{ Gender (\%) } & Chi-Square Test \\
\hline Have interest to treat people \& improve their oral health & $\begin{array}{l}\text { Female (81.4) } \\
\text { Male (60.0) }\end{array}$ & $p=0.022$ \\
\hline Dentistry has high-level income of practice & $\begin{array}{l}\text { Female (51.4) } \\
\text { Male (75.0) }\end{array}$ & $p=0.033$ \\
\hline Dentistry pays better than other job options available to me & $\begin{array}{l}\text { Female (28.6) } \\
\text { Male (65.0) }\end{array}$ & $p<0.001$ \\
\hline
\end{tabular}

\section{Discussion}

Online questionnaires have many advantages, such as ease of distribution, lack of human errors in entering data, control of the research timing and instant generation of results. However, they have a reasonably low response rate. The current study reveals a response rate of $67 \%$, which is relatively superior to many published articles, which used paper based questionnaires ${ }^{5,16}$. The response percentage was calculated out of the total number of officially registered students holding a University ID number. Nevertheless, according to the college attendance register, a small percentage of the first year students $(<6 \%)$ had never attended any classes, at least up to the time of deactivation of the online questionnaire link and this would reduce the response rate to some extent. It is worth mentioning that in this study there were no missing data, double answered questions or incomplete responses. In fact responses with those discrepancies were rejected by the system and not included in the total number of respondents.

It is probably a misleading approach to include all academic years of a program in a survey probing motivations for the choice of a dental career. This would probably provide deceptive outcomes. A factor that would make a student enroll in dentistry today might change over subsequent academic years. It is not unusual for a candidate to develop a different attitude towards the profession in his/ her later years of study. This is quite evident in a previous study that included all students from year one to year five ${ }^{13}$.

The current study included two academic years: year one (fresh students) and year two (just finished year one). The two classes form $50 \%$ of the total number of RAKCODS students. In the present study the number of female (63.6\%) students exceeded the males (36.4\%). This trend has been noticed in many countries including Brazil $^{6}$, United States ${ }^{9}$ and Denmark ${ }^{10}$, and stirred debate about feminization of dentistry ${ }^{18}$. The top three main motivations of the participants towards enrolling in the dental career were "treatment of people and improvement of their oral health $(73.6 \%)$ ", "dental practice is a combination of hand skills and knowledge (66.4\%)" and "dental profession provides option to be self-employed $(61.8 \%)^{\prime \prime}$. Interestingly, the females demonstrated higher motivation towards community services compared to the males. Helping people and improving of oral health (Altruistic motives) variable were rated as the most important factor by the female students and revealed a statistically significant difference $(p=0.022)$. This finding is in agreement with several previous reports $9,10,18$. Dentistry is a profession which inspires knowledge and hand skills; therefore, it is of no surprise to see considerable participants opting for dentistry as their future career. On the contrary, Brand and others ${ }^{7}$ explored the motives of the first year dental students in the University of Sydney, but noticed that skills, science and knowledge were the least important motives among the surveyed 
students. The authors stated that there were many inconsistencies in their findings reflecting subjective rather than objective criteria selection by the students.

The dental profession stands as a specialized field and enables fresh graduates to establish their own dental practice, thus the high valued concept of self-employment. In addition to the current study, many others ${ }^{18-21}$ found similar motive strength among the respondents.

A dental career is very attractive occupation and well-known for its high revenues. A substantial number of male students expressed their motives to study dentistry for financial gain and revealed a statistically significant difference when compared to female students $(p=0.033)$. This finding is in agreement with a similar regional study ${ }^{13}$. Furthermore, dental practice is not the only wellpaid profession. However, in contrast to female respondents, more than half of the male students who preferred dentistry as their future career believed that the dental profession would pay far better than any other potential jobs $(p<0.001)$. In the Middle East culture, males are responsible for most of family expenditures whereas females are invariably dependent and this probably reflects the low financial concerns expressed by females as a priority for job preference. It appears that, when it comes to career decision males are likely to be motivated by working conditions and financial gain while females by altruistic and human factors, a view that is shared by other reports as well ${ }^{13,22}$.

A private dental practice has the merit of time flexibility. This would make practitioners able to adjust their working schedule and find sufficient time to be with their families. Du Toit et al. ${ }^{3}$, reported that "leaving time for family life" was the first and strongest motivation for the surveyed students in the United States, Taiwan, Singapore, South Africa and Australia. In our study, more than half of the respondents, particularly the females considered this factor as crucial in taking a dental career decision.

Another factor that might have influenced the students in their career choice was prestige. Dentists provide an essential oral health care service. Furthermore, the patients' oral welfare and much of their total well-being is in the dentists' hands; thus the profession occupies a highly respected position within the community. Over $50 \%$ of the respondents rated prestige as an important factor for their career choice. This is in accordance with several previous reports ${ }^{2,3,23}$. Nevertheless, others found that prestige was the least important motive ${ }^{24,25}$. This probably reflects the range of social differences. In many countries including USA and UK the title "Doctor" is reserved for medical professionals or for those holding a $\mathrm{PhD}$ degree, while in the Middle East, the title is also used for dentists and this probably inspires motivation towards a dental career.

In UAE there are four accredited dental colleges providing undergraduate programs, each has its own curriculum, admission criteria and fees structure. This diversity may induce preferences among applicants for dental colleges. Therefore, the second part of the survey sought answers to questions related to RAKCODS (Table 2).

Probably this is the first study in the region to include another element of motivation in a survey querying for dental career, the "INSTITUTE". In 2011, the RAKCODS curriculum was completely revamped. Several new courses were added, clinical training credit hours were increased and the final year ends up with the submission of mandatory research project. Moreover, in Sep 2012 the college launched a new building complex with state of the art facilities. The survey revealed that $48 \%$ of the respondents chose RAKCODS because of the curriculum structure that meets their own country requirement and matches international standards. Many of the RAKCODS students are expats and approval of the curriculum by the authorities of their countries is essential for the recognition of the BDS degree. A similar percentage of students $(47 \%)$ were attracted by the fascinating building and associated facilities. The new students invariably visit the RAKCODS site and take a tour with their families before officially enrolling in the program to ensure satisfaction.

The other issue that might influence the students' admission or choice of a discipline is tuition. RAKCODS tuition remains the most reasonable compared to other dental colleges in UAE. About $27 \%$ of the respondents might have considered RAKCODS for a dental career because of tuition. It appears that about $20 \%$ of the surveyed students failed to get admission in other dental colleges, so that was the reason they chose RAKCODS. One fact remains unresolved in UAE with regard to admission to Universities. Students studying the British curriculum usually get their IGSC grades in mid-August and by mid-July all dental colleges would have filled their allocated seats, leaving those IGSC students with no chances for admission until the next academic year.

\section{Conclusion}

The present study describes the diverse demographic background of the RAKCODS students. The motivations seemed to be associated with the socioeconomic aspects of dentistry. The main motives were the interest to treat and improve people's oral health, dentistry is a knowledge and skill-based profession, dentistry generates a potential high income and dentistry provides self-employment, and it is a career that provides adequate time to be with one's families. There were statistically significant differences in motivation between males and females with financial factors more influential for males, and altruistic factors for females. With regard to the factors that may have influenced the choice of RAKCODS as the "INSTITUTE" for a dental career, the curriculum and fascinating facilities were the most attracting factors. 


\section{Acknowledgments}

The authors declares no conflict of interest related to this study. There are no conflicts of interest and no financial interests to be disclosed.

\section{REFERENCES}

1. Available from: http://rak.ae/en/web/rakportal/history. Accessed on 27.02.2015

2. Avramova N, Yaneva K, Bonev B. First-year dental students' motivation and attitudes for choosing the dental profession. Acta Med Acad. 2014;43(2):113-121

3. Du Toit J, Jain S, Montalli V, Govender U. Dental students' motivations for their career choice: an international investigative report. J Dent Educ. 2014;78(4):605-613.

4. Rashid H, Manoharan A, Abufanas S, Gallagher JE. Motivation for a career in dentistry: the views of dental students in the United Arab Emirates. Int Dent J. 2013;63(5):259-265.

5. Banabilh SM. Career decisions of undergraduate dental students at the University of Science and Technology, Yemen. J Dent Educ. 2013;77(3):331-336.

6. Freire Mdo $C$, Jordao LM, de Paula Ferreira $N$, de Fatima Nunes M, Queiroz MG, Leles CR. Motivation towards career choice of Brazilian freshman students in a fifteen-year period. $J$ Dent Educ. 2011;75(1):115-121.

7. Brand AA, Chikte UM. Choosing dentistry as a career-Part I: A comparison of student motives. J Dent Assoc S Afr. 1992;47(11):469-473.

8. Chattopadhyay A, Deol RS. Reasons for choice of dentistry as a career in Calcutta: a survey report. Indian J Dent Res. 1990;2(1):140-144

9. Scarbecz M, Ross JA. Gender differences in first-year dental students' motivation to attend dental school. J Dent Educ. 2002;66(8):952-961.

10. Vigild M, Schwarz E. Characteristics and study motivation of Danish dental students in a longitudinal perspective. Eur J Dent Educ. 2001;5(3):127-133

11. Butters JM, Winter PA. Professional motivation and caree plan differences between African-American and Caucasian dental students: implications for improving workforce diversity. J Natl Med Assoc. 2002;94(6):492-504

12. Khami MR, Murtomaa H, Jafarian M, Vehkalahti MM, Virtanen Jl. Study motives and career choices of Iranian dental students. Med Princ Pract. 2008;17(3):221-226.

13. Al-Bitar ZB, Sonbol HN, Al-Omari IK. Reasons for choosing dentistry as a career by Arab dental students. Eur J Dent Educ. 2008;12(4):247-251.
14. Gallagher JE, Patel R, Donaldson N, Wilson NH. The emerg ing dental workforce: why dentistry? A quantitative study of final year dental students' views on their professional career. BMC Oral Health. 2007:7:7.

15. Lalloo R, Ayo-Yusuf OA, Yengopal V. Early-phase dental students' motivations and expectations concerning the study and profession of dentistry. SADJ. 2008;63(4):216-220.

16. Vahid Dastjerdi M, Mahdian M, Vahid Dastjerdi E, Namdari M. Study motives and career choices of Iranian medical and dental students. Acta Med Iran. 2012;50(6):417-424.

17. McKay JC, Quiñonez CR. The feminization of dentistry: implications for the profession. J Can Dent Assoc. 2012:78:c1.

18. Jaiswal AK, Pachava S, Sanikommu S. Why dentistry? A crosssectional study of budding dentists in Andhra Pradesh. International Journal of Scientific Study. 2014;1(6):17-21.

19. Hallissey J, Hannigan A, Ray N. Reasons for choosing dentistry as a career--a survey of dental students attending a denta school in Ireland during 1998-99. Eur J Dent Educ. 2000;4(2):7781

20. Crossley ML, Mubarik A. A comparative investigation of dental and medical student's motivation towards career choice. $\mathrm{Br}$ Dent J. 2002;193(8):471-473.

21. Rashmi M, Virjee K, Yadava TS, Vijayakumar N, Shoba M Dentistry as a career: Motives and perception of dental students attending Dental Colleges in Bengaluru city, Karnataka, India. J Indian Assoc Public Health Dent. 2014;12(3):194-198.

22. Bourzgui F, Abidine Z, Serhier Z, Diouny S, Bennani Othmani M. Motivational factors influencing career choices of Moroccan dental students. Oral Health Dent Manag. 2014;13(2):390-394. 23. Anbuselvan GP, Gokulnathan S, Praburajan V, Rajaraman G Kumar SS, Thagavelu A. A study among dental students regarding the factors influenced dental students to choose dentistry as career. J Pharm Bioallied Sci. 2013;5(Suppl1):S36-8.

24. Brand AA, Chikte UM, Thomas CJ. Choosing dentistry as a career--a profile of entering students (1992) to the University of Sydney, Australia. Aust Dent J. 1996:41(3):198-205.

25. Nwhator SO, Olatosi O, Ashiwaju MO, Isiekwe Gl. Emerg ing trends in dental specialty choice in Nigeria. Int Dent $\mathrm{J}$. 2013;63(2):91-96.

\section{Juma ALKHABULI \\ BDS, MDentSci, MFDS RCPS, FICD, PhD, Associate Professor Chair of Basic and Medical Sciences Department \\ RAK College of Dental Sciences Ras Alkhaimah Medical and Health Sciences University - RAKMHSU Ras Alkhaimah, UAE

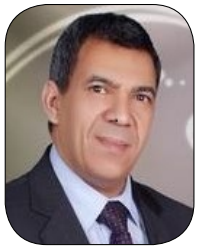

Dr. Alkhabuli was awarded his BDS degree by the University of Garyounis, Libya (1985). After graduatation he joined the ministry of health and, while working as a general dental practioner until 1998, he gained most of his clinical experience. He was also appointed director of the Aujillah health center, head of the Oasis medical and dental association, director of the dental section of the SIRTCO medical department.

The Leeds Univeristy, UK awarded him his MDS and also his PhD in oral pathology (2001-2005). He is also a Member of the Faculty of Royal College of Physician and Surgeons (Glasgow), UK and Fellow of the International College of Dentists.

His main research interest is the role of immunosurveillance cells in oral tumours and he has published several papers on this topic. 


\section{0uestions}

Mainly, the female students are highly motivated to study dentistry to:

口a. Improve their income;

b. Be a self-employed practitioner;

c. Treat and improve peoples' oral health;

d. Have a flexible working schedule.

\section{The majority of students have chosen RAKCODS to study dentistry because:}

$\square$ a. The curriculum matches the international standard;

b. Tuition fees are affordable;

$\square$ c. Could not get admission to another dental colleges;

$\square$ d. Easy to commute to the college.

Which of the following is second most preferred high school curriculum by RAKCODS students?

$\square$ a. The Australian curriculum;

b. The American curriculum;

$\square$ c. The Persian curriculum;

$\square$ d. The British curriculum.

\section{In contrast to female students, what is the main male students' motivation to study dentistry?}

口a. "There is not much on call work" for dentists;

ab. A dental job pays better than other jobs;

$\square$ c. Their parents are dentists;

$\square$ d. It is easy to get a job. 